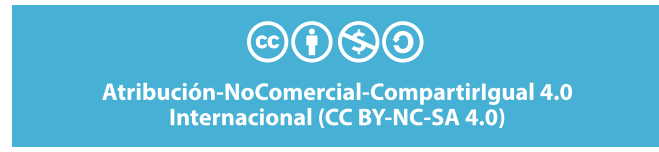

\author{
Leaned Matos Hidalgo ${ }^{1}$ \\ Yordan Chávez Ramírez ${ }^{2}$
}

DOI: http://dx.doi.org/10.20983/reij.2021.2.6

\title{
A CONTRALUZ: LAS INSPECCIONES E INTERVENCIONES CORPORALES EN LA INVESTIGACIÓN DEL PROCESO PENAL CUBANO
}

\author{
Against the light: Inspections and bodily interventions in the investigation of the Cuban \\ criminal process
}

\section{Resumen}

La investigación aborda los presupuestos teóricos, normativos y comparados acerca de las inspecciones e intervenciones corporales. Se pone de manifiesto su necesaria y correcta formulación como diligencias de investigación en el proceso penal cubano, debido a que se generan dificultades en la práctica jurídica con su aplicación. Se define como objetivo general fundamentar el perfeccionamiento de la realización de las inspecciones e intervenciones corporales, a partir del análisis teórico-práctico en aras de la protección de los derechos fundamentales de los procesados y víctimas del delito. Se utilizan como métodos científicos generales el análisis-síntesis e inductivo-deductivo. Como métodos específicos, el análisis jurídico comparado, el histórico jurídico, exegético jurídico y el teórico jurídico. Los resultados son la sistematización teórica de los fundamentos y elementos conceptuales acerca de las inspecciones e intervenciones corporales, a partir de los argumentos de la doctrina internacional y nacional y propuesta de pautas normativas con relación a la modificación de la Ley de Procedimiento Penal cubana con respecto a las inspecciones e intervenciones corporales.

Palabras claves: inspecciones corporales, intervenciones corporales, debido proceso, derechos humanos, disposiciones normativas

\section{Abstract}

The research deals with the theoretical, normative and comparative assumptions about body inspections and interventions, which shows their necessary and correct formulation as investigative measures in the Cuban criminal process, because your application is complicate in the juridical practice. It is defined as

1 Licenciada en Derecho. Diploma en Formación de Fiscales. Diploma en Derecho Penal. Ex fiscal de la Provincia Granma. Profesora Asistente de Derecho Procesal Penal y Coordinadora de Carrera de Derecho de la Facultad de Ciencias Económicas y Sociales de la Universidad de Granma, República de Cuba. Trabajo investigativo resultado del Proyecto "Convencionalidad y criminalidad", realizado en el 2019 en la provincia de Santiago de Cuba por el Departamento de Ciencias Penales y Derecho de la Empresa. Correo electrónico: Imatosh@udg.co.cu. ORCID: 00000002-4182-1732

2 Estudiante de pregrado que colaboró en la investigación a través de la realización de su Trabajo de Diploma. Universidad de Granma, República de Cuba. 
a General Objective: Basing the perfecting of the realization of the inspections and corporal interventions, as from the theoretic practical analysis for the sake of the protection of the organic laws of the defendants and victims of the crime. The general methods are used: Analysis-Synthesis and Inductive-Deductive, and specifics methods: Comparative Legal, Legal History, Legal Exegetical and Legal Theoretical. The results are: Theoretical systematization of the fundamentals and conceptual elements about body inspections and interventions, based on the arguments of international and national doctrine and Proposal normative guidelines regarding the modification of the Cuban Criminal Procedure Law with respect to body inspections and interventions.

Key Words: body inspections, body interventions, due process of law, human's rights, normative dispositions.

\section{Introducción}

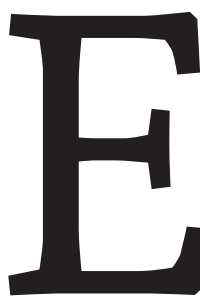

l derecho penal y en especial el proceso penal por antonomasia constituyen per se una limitación a los derechos fundamentales de los ciudadanos involucrados en él (Carnelutti, 1960). Por ende, el proceso penal, como conjunto de actos procesales encaminados a la investigación, la formulación de una imputación, el juzgamiento y la imposición de sanción o absolución del acusado por la comisión de un hecho delictivo, debe estar premiado de garantías que permitan a los sujetos implicados el respeto de sus derechos. Máxime si se necesita la vulneración de algunos, como el derecho a la intimidad, de víctimas y acusados, para el esclarecimiento del ilícito penal.

En relación con este asunto, Medina Batista (2015) refiere:

Que el debate existente entre el derecho legítimo de castigar del poder punitivo del Estado, concretado en el proceso penal y la idea de que este se pueda erigir 
como el instrumento idóneo de realización de las garantías de los derechos fundamentales de los derechos humanos, nos enfrenta a una realidad que obliga a la búsqueda de métodos adecuados para administrar justicia. (s.p.)

Se puede decir que durante los últimos años el derecho procesal penal, como ciencia autónoma, ha perfeccionado el contenido de las instituciones que conforman los sistemas de enjuiciar y el proceso penal en sí, estableciendo límites en cuanto al actuar de los órganos del Estado que realizan la investigación penal. Es por eso que se han fortalecido los principios de oportunidad, igualdad de las partes, presunción de inocencia y el derecho a la defensa técnica y material. Por ello, se delimitan las intervenciones e inspecciones corporales como diligencias de investigación en el proceso penal.

Las acciones indispensables realizadas sobre el cuerpo humano vivo (por el instructor, el cuerpo policíaco o el perito, con limitaciones de tratos crueles, inhumanos y degradantes, y con la finalidad de aseverar un resultado en la investigación de un hecho) representan una violación de derechos personalísimos, pero que son proporcionales al bien jurídico protegido por el derecho penal. En este sentido, la configuración y tratamiento legal de las mismas, en el aparato de justicia penal, merecen atención, en pos de respetar los derechos de los procesados y víctimas de los delitos. Potenciar los principios de proporcionalidad, necesidad e idoneidad, ofrecer garantías procesales y lograr un mayor índice de humanización en la investigación penal.

En relación con ello, el tema propuesto es novedoso en el sentido de la pobre producción investigativa acerca de este aspecto dentro del proceso penal y, sobre todo, la inexistencia de una propuesta científica que formule pautas para la configuración y tratamiento legal de las intervenciones e inspecciones corporales en el ordenamiento penal cubano. Es menester señalar que la doctrina internacional y nacional muestran criterios acerca de este tema, no obstante, se tratan en este trabajo otros aspectos no señalados anteriormente.

Es una materia actual, pues la doctrina procesal contemporánea, en el orden de lo penal, ha centrado sus valoraciones y argumentos en cuanto a modificación y perfeccionamiento de los modelos del proceso penal y los sistemas de enjuiciar, en el restablecimiento de la legalidad vulnerada por el responsable penal, evitar la victimización secundaria y proteger los derechos personales del acusado, elementos que igualmente se corporifican en esta investigación.

Esta investigación permite realizar un análisis del estado actual de las intervenciones e inspecciones corporales en cuanto procedimiento y régimen legal, lo que fundamenta y demuestra la necesidad de 
cambios normativos en la legislación penal adjetiva a partir de la entrada en vigor de una nueva constitución.

En este caso, se trata de dos instituciones que se utilizan en la etapa de investigación dirigida por el instructor, que no se encuentran formuladas en la ley rituaria, por lo que conlleva a violaciones de procedimiento, teniendo en cuenta los principios establecidos en el debido proceso y, por lo tanto, a la existencia de actos procesales nulos o anulables. Se aprecia, que los factores más influyentes en esta omisión son el desconocimiento de sus ventajas y las limitaciones legales del procedimiento en sede penal, cuestiones que no ayudan en el enfrentamiento y control del delito con el respeto de los derechos de los procesados y que, por el contrario, van en incremento de un sistema penal sin garantías e injusticias penales.

Se considera que, a través del reajuste de las formas de proceder, en relación con estas dos diligencias, es uno de los métodos para concretar un proceso penal más eficiente, lo que necesariamente se enfoca en la actualización y perfeccionamiento del ordenamiento jurídico cubano, consideraciones señaladas como prioritarias por nuestra dirección política y estatal en la implementación de los Lineamientos de la Política Económica y Social del Partido Comunista de Cuba.

\section{Metodología}

Por los argumentos expuestos, se propone como problema científico la incorrecta formulación legal de las inspecciones e intervenciones corporales que conllevan a la vulneración de los derechos personalísimos de los procesados y víctimas en el proceso penal cubano. De igual manera, se define como objetivo general fundamentar el perfeccionamiento de la realización de las inspecciones e intervenciones corporales a partir del análisis teórico-práctico en aras de la protección de los derechos fundamentales de los procesados y víctimas del delito.

Se proponen como objetivos específicos:

1. Sistematizar doctrinalmente las tendencias procesales acerca de las inspecciones e intervenciones corporales, a partir del examen de las obras de los principales exponentes en este tema, para que puedan establecerse los fundamentos que legitiman su ejecución en los procesos penales.

2. Caracterizar la regulación de inspecciones e intervenciones corporales en los procesos penales en Latinoamérica, a partir de un estudio comparado de las legislaciones procesales y el Código Procesal Modelo para Iberoamérica, para que puedan servir de base en el perfeccionamiento del sistema procesal penal cubano. 
3. Evaluar la ejecución de las inspecciones e intervenciones corporales en los procesos penales en Cuba, teniendo como base su regulación legal para la proposición de pautas normativas que contribuyan al perfeccionamiento del sistema procesal penal cubano.

Se establece como campo de la investigación a las diligencias de investigación en el proceso penal cubano y, como objeto de la investigación, las inspecciones e intervenciones corporales. Los métodos y técnicas que se utilizan son:

Métodos del nivel teórico de las ciencias en general:

1. Análisis-Síntesis: contribuye al análisis de cada una de las variables de la investigación vinculadas a las inspecciones e intervenciones corporales y sintetizar los principales fundamentos acerca del tema.

2. Inductivo-Deductivo: permite realizar conclusiones lógicas a partir de tendencias y razonamientos, partiendo de lo general a lo particular y de lo particular a lo general, o sea, de las diligencias de investigación hasta llegar a las inspecciones e intervenciones corporales, así como desde las posibles pautas acerca de su configuración.
Métodos del nivel teórico de las ciencias jurídicas:

1. Jurídico comparado: accede a comparar y analizar tendencias y criterios basados en disposiciones normativas pertenecientes a otros ordenamientos jurídicos respecto a las inspecciones e intervenciones corporales en los procesos penales.

2. Histórico jurídico: permite una exposición analítica de la evolución histórica que ha tenido la ejecución de las inspecciones e intervenciones corporales en el proceso penal.

3. Exegético jurídico: permite el análisis y caracterización de la norma procesal en los casos de realización de las inspecciones e intervenciones corporales en los procesos penales.

4. Teórico jurídico: admite un análisis, según la doctrina, de las inspecciones e intervenciones corporales en el proceso penal.

Técnicas:

1. Análisis de documentos: en virtud de esta técnica, se procederá al estudio de disímiles normas procesales y sustantivas penales y civiles del ámbito nacional y extranjero, con respecto a las inspecciones e intervenciones corporales en el proceso penal. 
2. Encuesta: esta técnica permitirá evaluar la ejecución de las inspecciones e intervenciones corporales, así como las posibilidades reales de perfeccionamiento en el referido proceso, teniendo como base la regulación actual que ofrece la Ley de Procedimiento cubana.

\section{Consideraciones generales acerca de las inspecciones e intervenciones corporales}

\section{Diligencias de investigación}

El derecho como producto social tiene su propia dinámica, pero cuando se trata de las personas a quienes se dirige el derecho, con la debida regulación de las conductas, estas están condicionadas a los escenarios jurídicos destinados a cumplir con la ley vigente, por lo que se instrumentalizan los mecanismos para que se ejecuten con el mayor nivel (Valdez, 2018). Huaylla (2015) expone que la búsqueda de la verdad en el proceso penal es una cuestión que por muchos años ha preocupado a la doctrina, existiendo posturas que creen en la búsqueda de la verdad formal, por un lado, y la búsqueda de la verdad histórica, por otro. Sánchez Carmona (1997) explica que se debe partir del concepto investigación, que surge del latín Investigium, In que significa sobre y Vestigium que significa vestigio, indicio, indicador, rastro, huella, o sea, ir sobre los vestigios, indicios, indicadores, rastros y huellas. Las nociones anteriores resaltan los actos de investigación o instructorios que, en la práctica forense, son denominados diligencias sumariales. Estos son actos de las partes y del juez de instrucción mediante los cuales se introducen en la fase instructora los hechos necesarios, bien para acreditar la existencia del hecho punible, su tipicidad y autoría, bien para evidenciar la ausencia de algún presupuesto condicionante de la apertura del juicio oral.

Landaverde (2017) conceptualiza a las diligencias de investigación como un procedimiento penal, dirigido con un carácter previo, que tiene por finalidad el pronto esclarecimiento de los hechos. En este sentido, se debe destacar que todos los autores señalados y otros (Florián, 1934; Horvitz Lennon y López Masle, 2003; Levenne, 1993; Moras Mom, 2004; Pedraz Penalva, 2002; Roxin, 2000; Vázquez Rossi, 1997) hacen alusión a los aspectos más generales en relación con las diligencias de investigación, discernimientos que se apoyan desde esta investigación. Teniendo en cuenta los aspectos aludidos (con los cuales se concuerda de manera general), se concluye que las diligencias de investigación, actos de investigación o acciones de instrucción son una serie de procedimientos llevados por un órgano del Estado en la fase preparatoria del proceso penal, con la finalidad de sustentar la acción penal, las que recaen sobre bienes, el imputado, víctima o tercero, teniendo como premisas principios y derechos fundamentales 
que no se pueden omitir. Para la presente, de ahora en adelante, diligencias de investigación. Nótese que dentro de estas diligencias cobran vida un conjunto de acciones realizadas por la administración a los sujetos, y que han sido divididas por el autor para una mejor comprensión en tradicionales y contemporáneas, dada la novedad de algunas y de la utilización de la tecnología en otras que las convierten en peripecias de esclarecimiento.

Diligencias de investigación tradicionales:

- Reconocimientos fotográficos: es una diligencia que se practica exhibiendo a las víctimas o testigos de los hechos, usando fotografías de sus archivos con el propósito de individualizar a los posibles culpables que no estén presentes ni puedan ser habidos (Cafferata, 2001).

- Presentación para reconocimiento.

- Dictamen pericial.

- La declaración del investigado, la misma se presta a una naturaleza compleja, en la medida que no solo sirve para el esclarecimiento de los hechos, sino que también es un medio de defensa (Morales, 2015).

- La entrada y registros.

- Inspección del lugar del hecho. El lugar de los hechos es el espacio abierto o cerrado, mueble o inmueble donde se cometió un presunto delito, incluyendo los alrededores, áreas adyacentes, lugares relacionados y rutas de escape (López, 2015).

- Declaración de testigos.

Diligencias de investigación contemporáneas:

- El agente encubierto.

- Las intervenciones médicas forzosas, en este contexto se recogen todos aquellos supuestos en que el sujeto se niega a recibir tratamiento médico requerido. Están presentes tambien las transfusiones sanguíneas a testigos de Jehová, así como las autoagresiones y suicidio frustrado (Duart, 2013).

- Las técnicas psicométricas.

- Técnica de la prueba P300, la cual puede definirse como una técnica neurofisiológica que a través de la electroencefalografía mide la actividad eléctrica positiva del cerebro (P) que aparece 300 milisegundos (300) después de que un individuo haya sido expuesto a un estímulo visual, auditivo, etc., de ahí su denominación como P300 (Rubio, 2016).

- La intervención de agendas o dietarios, también conocida como registro de libros y papeles, que igualmente está limitada por el derecho a la intimidad (Morales, 2015).

- Vigilancias y la obtención de grabaciones videográficas.

- La obtención de datos de carácter personal. 
- Inspecciones e intervenciones corporales. Este tipo de diligencias es una de las más usadas en la actualidad por la mayoría de los códigos procesales de muchos países.

Son aquellas diligencias que tratan de conseguir el descubrimiento de la verdad material en la fuente probatoria del cuerpo humano, bien sea de la víctima, del sospechoso o de un tercero. Dichas diligencias también están limitadas por derechos fundamentales y principios que amparan al ciudadano de los poderes coactivos de la Administración Pública, son las que ocupan este trabajo (Albiñana, 2016).

\section{Intervenciones e inspecciones corporales}

Al hablar de diligencias en relación con el cuerpo humano, González Jiménez (2014) refiere que son diligencias que, en ocasiones, pueden comprometer la integridad física y siempre van a tener una incidencia sobre el derecho a la intimidad, de una forma más o menos intensa.

Las intervenciones corporales consisten en aquellas medidas de inspección, registro o de tratamientos diversos sobre la interioridad del cuerpo humano vivo, incluyendo la exterioridad al desnudo de sus partes pudendas, que se practican sobre la parte, el imputado o un tercero (testigo o víctima), limitadas por la prohibición de tratos crueles, inhumanos y degradantes, aunque puedan restringir, bajo condicio- namientos constitucionales, derechos fundamentales como a no ser molestado en su persona o la autonomía personal, con el fin exclusivo de constatar o revelar hechos que sirvan de fuente o medio de prueba en el proceso penal (Brito Febles, 2009).

Según Cerrada Moreno (2010), al tratarse de medidas restrictivas de los derechos fundamentales, su licitud y, por tanto, su validez probatoria en el seno del proceso, dependen del respeto de medidas y de la observancia de los requisitos jurisprudencialmente establecidos. De igual manera, las inspecciones corporales son medidas restrictivas de los derechos lo que, de forma menos invasiva, sobre el cuerpo humano, según la doctrina, también se pueden llamar cateo, requisa, registro personal o el llamado cacheo.

Según el Diccionario de la Real Academia Española (2007), la palabra requisa tiene su origen en el francés réquisition y significa "revista o inspección de las personas o de las dependencias de un establecimiento" y "expropiación por la autoridad competente de ciertos bienes de propiedad particular, aptos para las necesidades de interés público" (s.p.). Dentro del contexto policivo, es el acto de palpación externa en el individuo, buscando evidencias delictivas. Para el Tribunal Constitucional Español, la diligencia de cacheo se define como "el registro de una persona para saber si oculta elementos que puedan servir para la prueba de un delito" (citado en Lucena, 2010). 
Para Gómez Orbaneja (1986) "la inspección corporal llevada a cabo para descubrir el cuerpo del delito, la cosa objeto de este, los instrumentos utilizados para su comisión y piezas de convicción, mediante un registro externo del cuerpo y la vestimenta del sujeto" (p.45).

Brito Febles (2009)

Aprecia que es una actividad policial que lleva consigo el acto de palpar superficialmente, al tacto manual, el perfil corporal del sospechoso de haber cometido un delito, con la finalidad de detectar armas $u$ otros instrumentos peligrosos para la vida o la integridad física de los funcionarios intervinientes o de terceros, de detectar piezas de convicción o efectos de la sospechada infracción penal, por lo general previo a la apertura del proceso penal. (p. 21)

Al respecto, Gimeno Sendra (1993) esclarece que los actos de investigación se deben de realizar a partir de los aspectos que definen el objeto del proceso, por lo que las intervenciones corporales se realizarían a partir de las características del proceso investigativo. Por eso las intervenciones corporales, al recaer sobre el interior del cuerpo humano en sus cavidades naturales o debajo de la piel o en la psiquis, se diferencian de las inspecciones corporales o las llamadas requisas o cacheos en que estos últimos recaen exclusivamente sobre la exterioridad del cuerpo humano, bien sobre las ropas o enseres que lleve consigo, e incluso sobre el cuerpo desnudo (Huertas, 1999).

De otra parte, las intervenciones corporales tienen la potencialidad de afectar la salud física o mental de las personas, por lo que siempre se va a requerir la ayuda de un experto en salud, según la naturaleza de la medida; incluso el registro al desnudo de las partes pudendas del cuerpo debe ser hecho por un facultativo de la salud. Es por ello que debe atenderse los posibles derechos a vulnerar, a decir de Ferrajoli (1999), de ese carácter esencial y básico de los derechos fundamentales así concebidos, se deriva su naturaleza de normas en sentido propio, que operan como vínculos y límites insalvables, para todos los poderes, públicos y privados.

Vázquez Ganoza (2005) menciona que la mayoría de las regulaciones legales están referidas exclusivamente a las intervenciones corporales, mas no a los registros de personas, pues estos últimos se configuran con la búsqueda externa sobre la vestimenta de la persona, equipaje o bultos que portase o el vehículo utilizado. Es decir, esto último se trata de un medio por el cual se registra a alguien para saber si oculta, siempre en el contorno o perímetro de su cuerpo, objetos de carácter delictual o relacionados con un delito.

Al realizar un análisis de los criterios expuestos, nótese que una diferencia im- 
portante entre ambos términos consiste en que los derechos que se ven restringidos de manera legítima son diferentes, el registro de personas se afecta, principalmente la intimidad, mientras que en la intervención corporal colisiona directa y principalmente con el derecho a la integridad física (Tribunal Constitucional Español, 1997). Se dice que no resulta afectado el derecho a la integridad física al no producirse, por lo general, lesión o menoscabo del cuerpo, pero sí puede verse afectado el derecho fundamental a la intimidad corporal siempre y cuando recaigan sobre partes íntimas del cuerpo, como, por ejemplo, un examen ginecológico (Constitución Española, art. 18.1).

\section{Principios que rigen estas diligencias como requisitos intrínsecos}

Vistos los requisitos de estas medidas, es válido aclarar que deben de estar presentes requerimientos para una correcta actuación. Esta debe ser idónea, necesaria y proporcionada. El principio de idoneidad para González Cuéllar (1990):

Constituye un criterio de carácter empírico inserto en la prohibición constitucional de exceso, que hace referencia, tanto desde una perspectiva objetiva como subjetiva, a la causalidad de las medidas en relación con sus fines y exige que las injerencias faciliten la obtención del éxito perseguido en virtud de su ade- cuación cualitativa, cuantitativa y de su ámbito subjetivo de aplicación. (p. 199)

Por el principio de necesidad, o también denominado intervención mínima, alternativa menos gravosa o de subsidiaridad, supone la necesaria utilización de otros medios menos lesivos para los derechos fundamentales, cuando ello sea posible debe estar justificada en el cumplimiento del fin estatal de hacer efectivos los derechos fundamentales, porque en la medida que se cometan delitos de especial gravedad, que afecten seriamente los derechos de las víctimas y el Estado no contase con los instrumentos para una adecuada respuesta a través de la justicia, estaría permitiendo la vulneración reiterada de los derechos fundamentales de los asociados que él está llamado a proteger.

Por último, se anota al principio de proporcionalidad, que es la argumentación donde se justifica las intervenciones e inspecciones en los derechos fundamentales, en aras de asegurar la prueba, no puede ser libre, sino que rigurosamente debe estar gobernada por premisas constitucionales, dependiendo del contexto en que se aplique el principio de proporcionalidad.

Si se quiere buscar un punto de unión entre los actos de investigación y los de prueba, este se encuentra recogido en el principio de proporcionalidad, sobre todo cuando en la realización de los mismos 
se afecta, aun mínimamente, un derecho fundamental (García Borrego, 2017).

Por lo tanto, en relación con el principio de proporcionalidad, en el caso concreto para determinar si este principio ha sido respetado, se deben ponderar dos parámetros: la gravedad o trascendencia social del hecho a investigar y las molestias o invasión de los derechos del sujeto sometido a aquella.

\section{Las inspecciones e intervenciones corpo- rales en el derecho comparado}

En el análisis comparado se escogió una muestra de la legislación más contemporánea y que sigue las directrices actuales del derecho procesal penal, esta incluye países como: República Federal de Alemania, Reino de España, República de Colombia, Estado Plurinacional de Bolivia, República del Salvador, República de Ecuador, República Bolivariana de Venezuela, República de Argentina y República de Brasil.

Los aspectos que se tuvieron en cuenta para realizar el análisis comparado fueron: 1) Reconocimiento de las inspecciones e intervenciones corporales como diligencias de investigación, 2) Regulación de los procedimientos especiales para la realización de las inspecciones e intervenciones corporales, 3) Observancia de los principios de idoneidad, necesidad y proporcionalidad, 4) Establecimiento de jurisdicción de garantías para la autorización de las inspecciones e intervenciones corporales.
El Código Procesal Penal Modelo para Iberoamérica ${ }^{3}$, en sus preceptos 37 y 38, realiza una síntesis de las inspecciones e intervenciones corporales, así como de los requisitos para su validez ${ }^{4}$, por lo que traza pautas, a nuestro entender, para el resto de las normas procesales del área.

El Código Procesal Penal Alemán ${ }^{5}$ regula en su Título II Contenido de las Diligencias de Investigación, Capítulo III Inspecciones e Intervenciones Corporales e Investigación Mediante ADN, artículo 281 regula los Registros corporales externos. En su artículo 282, se refiere al examen radiológico y en el 283 la exploración y observación de cavidades vaginal y rectal. En relación con las intervenciones corporales, el artículo 284 del mencionado código, obliga a seguir determinados protocolos.

La Ley de Enjuiciamiento Criminal Española ${ }^{6}$ establece en su Título V De la comprobación del delito y averiguación del delincuente, en sus artículos 356 y 359 , aspectos relacionados con las intervenciones corporales, en el primero, relacionado con las operaciones de análisis químico que exija la sustanciación de los procesos

3 Código Procesal Penal Modelo para Iberoamérica. Tomado de http://iibdp.org/images/C\%C3\%B3digos\%20Modelo/IIDP_C\%C3\%B3digo_Procesal_Penal_Modelo_Iberoam\%C3\%A9rica.pdf.

4 37. Examen mental obligatorio. 38. Investigación corporal.

5 Código Procesal Penal Alemán. Tomado de: https:// www.marcialpons.es/.../codigo-penal-aleman...codigo-procesal-penal- aleman.../9788472487574/.

6 Ley de Enjuiciamiento Criminal Española. Tomada de: https://confilegal.com/20171101-ley-enjuiciamiento-criminal-actualizada/. 
criminales y el segundo en relación con los requisitos del informe de los resultados.

En Colombia, el Código de Procedimiento Penal aprobado por la Ley 906 de 20047 , regula como actuaciones que requieren autorización judicial previa para su realización que las mismas implican afectación de derechos y garantías fundamentales como la inspección corporal, registro personal, la obtención de muestras que involucren al imputado y los reconocimientos y exámenes físicos de las víctimas. ${ }^{8}$

El Código Procesal de Bolivia9 es claro y preciso en cuanto a estas diligencias. Refiere primeramente a las garantías constitucionales del acusado, haciendo una aplicación directa de la Ley Fundamental, de esta forma, cuando a la persona que se le va a realizar este tipo de diligencias, el código boliviano versa sobre el respeto al derecho de la dignidad humana. ${ }^{10}$

También refiere a que, en caso de requisas personales, el fiscal podrá disponer de las mismas, pero no con libre albedrío, sino cuando haya motivos suficientes para sospechar que una o más personas ocultan

7 Código de Procedimiento Penal colombiano. Tomado de https://leyes.co/codigo_de_procedimiento_penal.htm.

8 Artículo 247. Inspección corporal. Artículo 248. Registro personal. Artículo 249. Obtención de muestras que involucren al imputado. Artículo 250. Procedimiento en caso de lesionados o de víctimas de agresiones sexuales.

9 Código de Procedimiento Penal de Bolivia. Tomado de: www.cicad.oas.org/fortalecimiento.../codigo_procedimiento_penal.pdf.

10 Artículo 175. (Requisa personal). Artículo 206. (Examen médico). entre sus pertenencias, o llevan en el interior de su cuerpo o adherido a él, objetos relacionados con el delito.

El código salvadoreño $0^{11}$ también hace alusión al tema cuando refiere a que, ante la presencia de fluidos corporales, cabellos, vello púbico u otro vestigio que permita determinar datos como la raza o el tipo de sangre en una escena del delito, el fiscal podrá requerir la realización de exámenes de ADN para el levantamiento de perfiles genéticos, pero teniendo en cuenta como requisito la solicitud del fiscal al juez para dicha diligencia.

Se regula, además, por este cuerpo normativo, que para realizar la inspección de una persona cuando advierta que sobre su cuerpo existen elementos o indicios de prueba, tal diligencia podrá realizarse, aun en contra de la voluntad de la persona, cuando se trate del investigado y en todo caso respetando su salud y la dignidad. Si fuere necesario, el acto se practicará con auxilio de peritos. ${ }^{12}$

Con relación al Código Orgánico Integral Penal de Ecuador ${ }^{13}$ regula en su artículo 4 que las y los intervinientes en el proceso penal son titulares de los derechos humanos reconocidos por la Constitución de la

11 Código Procesal Penal del Salvador. Tomado de http://www.asamblea.gob.sv/eparlamento/indicelegislativo/...de.../codigo-procesal-penal.

12 Dignidad humana.

13 Código Penal Integral de Ecuador. Tomado de http:// www.justicia.gob.ec/wpcontent/uploads/2014/05/ c\%C3\%B3digo_org\%C3\%A1nico_integral_penal_-_ coip_ed._sdn-mjdhc.pdf. 
república y los instrumentos internacionales, de igual manera, con relación a las inspecciones e intervenciones corporales en su artículo 459, preceptúa la necesaria autorización de la persona o del juzgador para la realización de obtención de muestras, exámenes médicos o corporales.

Por su parte, Venezuela en su Código Orgánico Procesal Integra ${ }^{14}$ regula en su artículo 10 el debido respeto a la dignidad inherente al ser humano, y en relación con las diligencias de investigación que se realizan sobre el cuerpo en los artículos 192 y 195.

El Código Procesal Penal de la Nación de Argentina ${ }^{15}$, establece en su artículo 175 sobre los exámenes corporales.

El Código de Proceso Penal de Brasil ${ }^{16}$ regula lo concerniente al examen corporal realizado por peritos en su artículo $158^{17}$, aunque de manera aislada y sin pormenorizar como otras legislaciones de la región.

Por todos los contenidos analizados se puede expresar quelas legislaciones procesales de Europa y América en su totalidad establecen los siguientes aspectos en relación con las inspecciones e intervenciones corporales: 1) Existe un reconocimiento

14 Código Orgánico Procesal Integral de Venezuela. Tomado de: https://www.unodc.org/.../codigo...procesal-penal.../CODIGO_ORGANICO_ PROCESAL_ PENAL_2012.pdf.

15 Código Procesal Penal de Argentina. Tomado de www.saij.gob.ar/docsf/codigo/Codigo_Procesal_Penal_de_la_Nacion.pdf.

16 Código de Processo Penal de Brasil. Tomado de: www.planalto.gov.br/ccivil_03/decreto-lei/del3689compilado.htm.

17 Capítulo II. Do exame do corpo de delito, e das perícias em geral. expreso de las mismas, 2) Se codifican los principios generales para la realización de las diligencias mencionadas, 3) Se prevén los procedimientos especiales, 4) Existe diversidad en la nominación del conjunto de diligencias que conforman las inspecciones e intervenciones corporales y 5) Se establecen en las normas procesales autoridades para autorizar las inspecciones e intervenciones corporales como son los Tribunales de Garantías y los Ministerios Fiscales en otros.

\section{Inspecciones e intervenciones corporales en Cuba}

Antecedentes históricos y legislativos acerca de las intervenciones e inspecciones corporales en Cuba

En relación con la investigación, se analizan solo los antecedentes más relevantes de la época colonial en Cuba, debido a que es donde se enmarca la legislación que reguló los actos correspondientes a los diversos procesos penales, entre ellos los relativos a las diligencias de investigación.

La Ley de Enjuiciamiento Criminal Española de $1882^{18}$ (LECrim en adelante), describió los procedimientos procesales en la Isla hasta 1973, la misma reflejó las diligencias de instrucción que son llevadas a cabo por una serie de instituciones que

18 Ley de Enjuiciamiento Criminal, promulgada por Real Decreto de 14 de septiembre de 1882 . Tomada de https://confilegal.com/20171101-ley-enjuiciamiento-criminal-actualizada/. 
representan a la administración pública. Ejemplo de ello, resulta que esta ley rituaria en su Título VIII hace una alusión al registro: De la entrada y registro en lugar cerrado, del de libros y papeles y de la detención y apertura de la correspondencia escrita y telegráfica. En correspondencia con ello, regula los artículos 545, 546, 552 y 579.

Este capítulo, la LECrim versa sobre aquel procedimiento a realizar en la diligencia del registro, entre los requisitos que resaltan se encuentra estar presupuestada por un previo auto judicial que ordene su ejecución, concurriendo el interesado o, en su defecto, personas designadas, además de los testigos que deben acompañar a los agentes de la policía. Por tanto, podemos observar con detalles que la LECrim ofrece pautas importantes en el tema en cuestión en su artículo 575, debido a que es un primer acercamiento al objeto de este trabajo investigativo, resulta suficiente para declarar que el legislador en su intención recogió lo relativo a la necesidad de realización de este acto, a partir de la importancia para la causa, de igual manera, lo relativo a la proporcionalidad con el hecho investigado, de ahí la repercusión penal que podría traer la negativa del inspeccionado.

Sin embargo, no se realiza una distinción específica a los momentos dentro de la investigación penal más certeros para realizar esta diligencia ni otras que de igual manera se ejecutaban, solo con el pa- recer del juez de instrucción, como la extracción de sangre, aspectos que quedaron para una futura regulación por el sistema de salud.

Con respecto a otros elementos en torno al debate de esta investigación esta ley no hace referencia.

\section{Análisis de las intervenciones e inspecciones corporales en el ordenamiento jurídico}

\section{Constitución de la república}

El punto intermedio que existe entre la constitucionalización normativa de los derechos fundamentales y el fortalecimiento de la independencia judicial es la articulación de una disciplina constitucional exigente del proceso, en especial del proceso penal.

En este sentido, la Constitución cubana de 1976, en el orden del debido proceso, estableció las pautas valorativas de cualquier análisis en este sentido, en el cual se estipula en el artículo 10 el principio de legalidad, en el contexto de cumplir lo reglamentado para el proceso y algunas regulaciones del debido proceso desde el artículo 56 hasta el 60 de la Constitución de la República de Cuba.

Se puede declarar que el legislador se atemperó a su época, por lo que conceptos como la dignidad humana y debido proceso $^{19}$, entre otros, no quedaron reflejados

19 Artículo 9. El Estado: garantiza la libertad y la dignidad plena del hombre, el disfrute de sus derechos, 
en el texto constitucional y, al pasar los años, se hizo necesaria una reforma que actualizara las normas constitucionales y añadiera aspectos esenciales del proceso penal que, sin duda, en cuestión de derechos humanos, son trascendentales, como lo son las intervenciones e inspecciones corporales.

Nuestra Constitución actual ${ }^{20}$, promulgada en 2019 (reforma total o parcial, criterio sobre el que no se precisará, debido a que no es centro de esta investigación), ha incluido artículos que sin duda alguna son superiores en cuanto la magnitud, la redacción y posibilidad de aplicación, por otra parte, son fruto del conocimiento popular, por lo que gozan de reconocimiento social.

Entre los que se pueden citar se encuentran los artículos 1, 10, 13 inciso d), 40, 41, 46 y 48, todos aportan elementos sobre la necesidad de respeto de la dignidad humana, la intimidad, en fin, derechos personalísimos que son irrenunciables e intransferibles. ${ }^{21}$

En torno a las garantías de estos derechos, regula en el Capítulo VI, Garantía de los derechos los contenidos del debido

el ejercicio y cumplimiento de sus deberes y el desarrollo integral de su personalidad.

Artículo 41. Todos los ciudadanos gozan de iguales derechos y están sujetos a iguales deberes.

Artículo 63. Todo ciudadano tiene derecho a dirigir quejas y peticiones a las autoridades y a recibir la atención o respuestas pertinentes y en plazo adecuado, conforme a la ley.

20 Gaceta Oficial de la República de Cuba Extraordinaria No.5 del 10 de abril de 2019.

21 Artículo 1, Artículo 10, Artículo 13, Artículo 40, Artículo 41, Artículo 46, Artículo 48. proceso, de esta manera establece que toda persona, como garantía de seguridad jurídica, disfruta de un debido proceso, por tanto, es claro que los derechos fundamentalísimos no pueden ser pisoteados por la Administración Pública, teniendo en cuenta que la sociedad es más dinámica que el derecho, con el tiempo surgen situaciones adelantadas a estas mismas leyes, situaciones que deben ser controladas por el Estado a través del ius puniendi, pero sin transgredir los derechos de otros, limitado por el principio de legalidad, en su artículo 94.

De igual manera, en su artículo 95, norma lo relativo al debido proceso penal, otorgándole orden constitucional a este particular, lo que proporciona vital importancia en relación a las inspecciones e intervenciones corporales los incisos d) e i), los que precisan que deben respetarse lo derechos de los procesados y de las víctimas, fundamentalmente los de la dignidad, la integridad física, integridad psíquica e integridad moral, lógicamente son derechos que rozan con un examen vaginal, examen anal, extracción de muestras de sangre, extracción de saliva y fluidos corporales, examen psicológico, examen psiquiátrico, entre otras diligencias de investigación que se realizan en la fase preparatoria del proceso.

Por otra parte, en relación con el control de la fase de investigación, refiere que será 
la Fiscalía General de la República de Cuba en su artículo 156.

En este orden, es lógico que da por sentado la norma constitucional, que todas las autorizaciones y controles de la legalidad realizados en la fase de investigación de nuestro proceso penal se realizan por dicho órgano.

En relación a la posibilidad de que las inspecciones o intervenciones corporales deben ser autorizadas por el órgano jurisdiccional, como otras legislaciones, no se establece nada al respecto, no obstante, en su artículo 99, regula otra posibilidad para en caso de que se violasen los principios y presupuestos para la realización de las inspecciones o intervenciones corporales de idoneidad, necesidad y proporcionalidad, y se lacerase algún derecho de los procesados o víctimas, cabría la posibilidad de instar al órgano jurisdiccional por una reparación o indemnización, que, a juicio del autor, podría traer como consecuencia una declaración de nulidad de estos medios probatorios en el proceso penal en cuestión.

\section{Ley de Procedimiento Penal y sus modificaciones}

En relación con el tema, la supra citada LPP, regula el dictamen pericial, los que tienen aspectos fundamentales en los artículos 200, 211, 213 y 214.

Es dable aclarar que la mayoría de las intervenciones corporales son realizadas por peritos, por tanto, sería en forma de dictamen pericial su concurrencia como medio de prueba al proceso penal, ahora bien, nuestra ley rituaria no es precisa en torno a las inspecciones e intervenciones corporales, mucho menos lo es con las garantías del ciudadano establecidas ya a nivel constitucional, lo que pudiera estar dado, por la actualidad de las normas constitucionales y la necesidad de atemperar la norma adjetiva, dispuesta ya en el calendario legislativo de la Asamblea Nacional del Poder Popular, y su presentación queda a cargo del Tribunal Supremo Popular, con el concurso de varios actores y partícipes de los procesos penales.

Relacionado con esto, establece como forma de las inspecciones corporales el conocido registro personal, requisa o cacheo en el artículo 230: "Toda persona requerida al efecto está obligada a exhibir los objetos y documentos que tenga en su poder y que puedan tener relación con la comprobación de un hecho delictivo" (Ley de Procedimiento Penal Cubana, 1977).

Sin dudas, es un claro reajuste del artículo 575 de la LECrim y una vaga y oscura posibilidad de realización de una inspección corporal que se realizaría por agentes de la policía o instructores penales sin la autorización debida por parte de la Fiscalía como encargado de la legalidad, por supuesto, debe analizarse, además, con objetividad, la necesidad de realizar la diligencia en un momento determinado que 
no se pueda esperar, lo que pudiera ser presentado posteriormente al encargado del control con el acta de inspección, regularizando de forma excepcional en los casos en los que deba realizarse de inmediato la inspección corporal.

En este sentido, se pone de relieve que no se muestran los artículos correspondientes ni se describen las intervenciones e inspecciones corporales como diligencias de investigación en momentos procesales como es la fase investigativa o de instrucción.

En relación con la praxis jurídica cubana, este tipo de diligencias sí se le realiza a sospechosos, acusados, víctimas y terceros que intervienen en el proceso penal debido a que, aunque en ocasiones se tornan invasivas e injerencistas de los derechos fundamentales, son necesarias para delimitar aspectos esenciales en delitos de violación, asesinato, pederastia con violencia, lesiones, entre otros.

Con respecto a este tema de diligencias de investigación, podemos citar al Decreto-Ley No. 389 de 2019 del Consejo de Estado, modificativo del Código Penal, Ley Contra Actos de Terrorismo y de la Ley de Procedimiento Penal, que ha incluido nuevos tipos de diligencias de investigación de carácter contemporáneo, no obstante, quedó pendiente la deuda en relación con las inspecciones e intervenciones corporales. Estas diligencias de investigación "se emplean siempre que resulten idóneas o necesarias para la investigación de hechos delictivos que por su gravedad, connotación u organización lo requieran, incluyendo operaciones cuyo origen o destino sea el exterior del país” (Ley Contra Actos de Terrorismo y de la Ley de Procedimiento Penal, 2019) ${ }^{22}$. Se observa, por un lado, un avance con respecto a la legalización de este tipo de diligencias que se tornan supremamente importantes en la fase investigativa procesal, pero, por otro, estas diligencias siguen realizándose sin una tutela judicial o legal efectiva, no interviene la presencia de un juez de garantías o de instrucción al dar la orden que impulse esta acción de instrucción ni la del fiscal como controlador de la investigación penal.

\section{Otras normativas}

En la práctica jurídica, las metodologías de trabajo de la Fiscalía ${ }^{23}$ y de Instrucción Penal $^{24}$ establecen claramente cada una de las diligencias de investigación a realizar y controlar en la fase preparatoria del

22 Decreto-Ley No. 389 de 2019. Modificativo del Código Penal, Ley Contra Actos de Terrorismo y de la Ley de Procedimiento Penal. Gaceta Oficial No.27 Extraordinaria de 18 de noviembre de 2019.

Artículo 110.1. Son técnicas especiales de investigación, a los efectos de esta ley, la investigación encubierta, el colaborador eficaz, el empleo de la vigilancia electrónica o de otro tipo y las entregas vigiladas; se emplean siempre que resulten idóneas o necesarias para la investigación de hechos delictivos que por su gravedad, connotación u organización lo requieran, incluyendo operaciones cuyo origen o destino sea el exterior del país.

23 Instrucción No.7 de 1999 de la Fiscalía General de la República.

24 Modelos de actuación interna que se establecen ante el traslado de detenidos, traslado de mujeres víctimas, metodologías de investigación de delitos. 
proceso penal, y estas hacen alusión a la variedad de inspecciones corporales, o registros corporales, cómo se señalan, y las intervenciones corporales.

De extrema importancia es la Ley No. 41 de Salud Pública ${ }^{25}$ y la Resolución Ministerial 100 de 2008 del MINSAP, en relación con la "Metodología para el funcionamiento de las comisiones provinciales de peritación psiquiátrica forense en el sistema nacional de salud" (Ministerio de Salud Pública, 2008) ${ }^{26}$.

Por otra parte, en la Resolución Ministerial de Salud Pública No. 458 de 2019²7, se establece la actualización de la metodología para la evaluación de la Responsabilidad Penal Médica vinculada a los procesos penales, lo que indudablemente está vinculado a la alta ocupación que tiene el personal de salud en algunas diligencias de investigación, en el dictamen pericial que realizan vinculado al esclarecimiento de hechos delictivos.

\section{Pautas generales para el perfecciona- miento}

Para el estudio práctico de las inspecciones e intervenciones corporales, se revisa-

25 Ley No. 41 de Salud Pública de 1983. Gaceta Oficial. Asamblea Nacional del Poder Popular en Sesión Ordinaria, celebrada el 13 de julio de 1983, correspondiente al Cuarto Periodo Ordinario de Sesiones de la Segunda Legislatura.

26 Resolución 100 de 2008 del Ministerio de Salud Pública. Tomada de https://salud.msp.gob.cu.

27 Resolución 458 de 2019 del Ministerio de Salud Pública. Tomada de https://salud.msp.gob.cu. ron 184 expedientes de fase preparatoria y rollos de expedientes de fase de los delitos de violación, pederastia con violencia, abusos lascivos, asesinato, homicidio, homicidio en ocasión de conducir vehículos por la vía pública, robo con fuerza en las cosas y robo con violencia e intimidación en las personas, en el periodo comprendido de 2014 hasta 2019; de ellos, en el $100 \%$ de las investigaciones penales, se realizaron varios tipos de inspecciones e intervenciones corporales, resaltando el registro personal, la extracción de sangre, recolección de fluidos vaginales, examen anal y vaginal y examen psiquiátrico.

De igual manera, se realizaron 37 encuestas a profesionales que ejercen en la esfera penal (instructores, médicos legistas, fiscales, abogados y jueces), el 100\% considera que las inspecciones e intervenciones corporales son diligencias necesarias e importantes para esclarecer los hechos delictivos; el 76\% expresa que las intervenciones corporales deben ser autorizadas por el fiscal o el Tribunal y debatidas en audiencia preliminar; el 94\% razona que las inspecciones corporales pueden ser realizadas por los agentes de la policía o instructores penales atendiendo a procedimientos específicos sin autorización de ninguna otra autoridad, de igual manera, en su totalidad considera importante regular el procedimiento para las mismas en la ley rituaria. 
En relación con los delitos que necesitan de la realización de las inspecciones e intervenciones corporales, resaltaron los de homicidio, asesinato, violación y pederastia con violencia en más del $92 \%$ y los de robo con fuerza en las cosas y robo con violencia e intimidación en las personas en un 84\%; en cuanto a las diligencias en sí, en un $100 \%$ coincidieron con las observadas en la revisión de los expedientes.

Ahora bien, teniendo en cuenta los resultados de la sistematización de la doctrina y la teoría, el derecho comparado y la evaluación de la puesta en práctica en nuestro país, se tiene a bien la realización de algunas pautas que sirvan de base al perfeccionamiento de nuestro proceso penal, en especial, en la fase de investigación, a partir del respeto de las garantías del acusado y los derechos de las víctimas y terceros intervinientes en el proceso. Estas son:

Con relación a la Ley de Procedimiento Penal:

1. Conceptualizar el debido proceso, a través del reconocimiento de los derechos y garantías del causado, las víctimas y los terceros intervinientes en el proceso, de una forma explícita. Describir los derechos fundamentales que pueden ser vulnerados en la investigación penal y bajo qué presupuestos.

- Derechos fundamentales: derecho a la libertad, derecho a la dignidad, a la integridad física y psíquica, la integridad moral, la intimidad, derecho a la autonomía personal, a la imagen y al honor.

- Presupuestos: idoneidad, necesidad, proporcionalidad.

- Principio de legalidad: dado en la existencia de todas las normas al respecto.

2. Regular en un capítulo independiente las inspecciones y las intervenciones corporales.

- Una sección primera "Inspecciones corporales" y una sección segunda “Intervenciones corporales".

- Delimitar qué acciones o diligencias de instrucción son inspecciones y cuáles son intervenciones corporales, y bajo qué principios se diferencian.

3. Designar a la autoridad competente para autorizar y realizar las inspecciones e intervenciones corporales.

- En el caso de las inspecciones corporales, solo la aprobación de instrucción penal.

- Para las intervenciones corporales debe constar autorización del fiscal, a partir de la solicitud justificada del instructor penal (a tenor de lo que establece la Constitución como función de la Fiscalía, la del control de la investigación, aspecto que puede ser modificado a solicitud ante el órgano jurisdiccional).

- En caso de negativa por parte del imputado, víctima o tercero de la reali- 
zación de la intervención corporal, o de existir violación de algún derecho fundamental de manera injustificada, resolver ante el órgano jurisdiccional.

4. Regular procedimiento específico y expedito para resolver cuestiones incidentales que se den en torno a la realización de las inspecciones e intervenciones corporales.

\section{Conclusiones}

1. Las intervenciones e inspecciones corporales son aquellas diligencias de investigación que se realizan en la fase de la investigación penal, las que deben de estar valoradas por los principios de proporcionalidad, necesidad e idoneidad para no transgredir los derechos fundamentales del ciudadano por parte de funcionarios y, a la vez, poner límites a los poderes coactivos del Estado y tratar a toda costa que la búsqueda de la verdad no se traduzca en quebrantar la legalidad.

2. Los códigos procesales de Europa y América Latina, en su mayoría, ilustran el reconocimiento legal de las intervenciones e inspecciones corporales, así como los principios, el procedimiento y pautas generales a realizar en aquellos momentos procesales donde se lleva a cabo este tipo de diligencias de investigación.

3. Existe ausencia de regulación de las intervenciones e inspecciones corpo- rales en el sistema procesal penal cubano, fundamentalmente en la Ley de Procedimiento Penal, la que se encuentra totalmente opuesta a lo que esboza nuestra Constitución en la actualidad, lo que no impide que se realicen a ultranza en la praxis jurídica dichas diligencias, que en ocasiones tocan con el límite de la legalidad.

4. La Ley de Procedimiento Penal cubana necesita de carácter urgente una modificación en la que se reconozcan las intervenciones e inspecciones corporales como diligencias de investigación en el proceso penal, sus tipologías, así como el procedimiento y la metodología a realizarlas con el fin de velar por la calidad del debido proceso, ser más garantistas y que no se mancillen los derechos de los ciudadanos.

\section{Referencias}

Albiñana Olmos, L, J. (2016). Las debilidades de los procesos penales nacionales. Las intervenciones corporales en el proceso penal. $\mathrm{Pu}$ blicaciones del Portal Iberoamericano de las Ciencias Penales, Instituto de Derecho Penal Europeo e Internacional. Universidad de Castilla-La Mancha. http://www.cienciaspenales.net_

Antillón Montealegre, W. (2012). El proceso penal. Estudios. Editorial Investigaciones Jurídicas.

Brito Febles, O. P. (2009). Intervenciones corporales vs Administración de justicia. Revis- 
ta Científica Equipo Federal del Trabajo. http:// www.newsmatic.epol.com.ar/index.php

Cafferata Nores, J. I. y Arocena, G. A. (2001). Temas de Derecho Procesal Penal (Contemporáneos). Editorial Mediterránea.

Carnelutti, F. (1960). Cuestiones sobre el proceso penal (S. Sentis Melendo, Trad.). Librería El Foro.

Castillero Arranz, J. V. (1998, del 4 al 6 de marzo). Vigencia e influencia del derecho penal español en el derecho penal cubano [conferencia]. Segundas Jornadas Internacionales de Iberoamérica C.M.H. Hernán Cortés, El 98: un punto de partida. España, Iberoamérica y Portugal. Universidad de Salamanca.

Cerrada Moreno, M. (1 de noviembre de 2010). Las intervenciones corporales. Noticias Jurídicas.http://noticias.juridicas.com/conocimiento/articulos-doctrinales/4596-las-intervenciones-corporales/.

Código de Procedimiento Penal colombiano. Tomado de https://leyes.co/codigo_de_procedimiento_penal.htm

Código de Procedimiento Penal de Bolivia. Tomado de http:// www.wipo.int

Código de Procedimiento Penal de Bolivia. Tomado de: www.cicad.oas.org/fortalecimiento.../codigo_procedimiento_penal.pdf

Código de Processo Penal de Brasil. Tomado de: www.planalto.gov.br/ccivil_03/decreto-lei/del3689compilado.htm

Código Orgánico Procesal Integral de Venezuela. Tomado de: https://www.unodc. org/.../codigo...procesalpenal.../CODIGO_ ORGANICO_PROCESAL_PENAL_2012.pdf.
Código Penal Integral de Ecuador. Tomado de: http://www.justicia.gob.ec/wpcontent/ uploads/2014/05/c\%C3\%B3digo_org\%C3\%A1nico_integral_penal_-_coip_ed._ sdn-mjdhc.pdf.

Código Procesal Penal Alemán. Tomado de: https://www.marcialpons.es/.../codigo-penal-aleman...codigo-procesal-penal- aleman.../9788472487574/

Código Procesal Penal de Argentina. Tomado de: www.saij.gob.ar/docsf/codigo/Codigo_ Procesal_Penal_de_la_Nacion.pdf

Código Procesal Penal del Salvador. Tomado de: http://www.asamblea.gob.sv/eparlamento/ indicelegislativo/...de.../codigoprocesalpenal Código Procesal Penal Modelo para Iberoamérica. Tomado de http://iibdp.org/ images/C\%C3\%B3digos\%20Modelo/IIDP_ C\%C3\%B3digo_Procesal_Penal_Modelo_ Iberoam\%C3\%A9rica.pdf

Constitución de la República de Cuba. G.O. Extraordinaria No. 3 de fecha 31 de enero de 2003, con las reformas aprobadas por la Asamblea Nacional del Poder Popular en el XI Periodo Ordinario de sesiones de la III Legislatura, 1992, 2005.

Constitución de la República de Cuba. Gaceta Oficial de la República de Cuba Extraordinaria No.5 del 10 de abril de 2019.

Constitución Española. Tomada de: https: // www.boe.es.

Decreto-Ley No.389 de 2019. Modificativo del Código Penal, Ley Contra Actos de Terrorismo y de la Ley de Procedimiento Penal. Ga- 
ceta Oficial No.27 Extraordinaria de 18 de noviembre de 2019.

Duart Albiol, J. J. (2013). Inspecciones, registros $e$ intervenciones corporales en el proceso penal. [Tesis doctoral, Universidad Autónoma de Barcelona]. Archivo digital. https://www. tdx.cat/bitstream/handle/10803/131291/jjda1de1.pdf

Ferrajoli, L. (1999). Derechos y garantías. La ley del más débil. (P. Andrés Ibáñez y A. Greppi

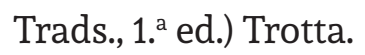

Florián, E. (1934). Elementos de derecho procesal penal. Editorial Bosch.

García Borrego, J. A. (2017). Análisis de la regulación y jurisprudencia actual de las Diligencias de Investigación en el Proceso Penal y la actuación de la Policía Judicial, en particular, la intervención de las nuevas modalidades de comunicaciones personales. [Tesis de doctorado, Universidad Católica de Murcia]. Archivo digital. http://www.investigacion.ucam.edu Gimeno Sendra, J. V. (1993) Derecho Procesal Penal. Tomo 2. Tirant lo Blanch.

Gómez Orbaneja, E. y Herce Quemada, V. (1986). Derecho Procesal Penal (10. ${ }^{\text {a }}$ ed.). Artes Gráficas y Ediciones.

González Jiménez, A. (2014). Las diligencias policiales y su valor probatorio. [Tesis de doctorado, Universidad de Rovira I Virgili]. Archivo digital. http:// www.tdx.cat_

González-Cuéllar Serrano, N. (1990). Proporcionalidad y derechos fundamentales en el Proceso Penal. Editorial Colex.

Horvitz Lennon, M. y López Masle, J. (2003) Derecho procesal penal chileno. Principios. Sujetos procesales. Medidas cautelares. Etapa de investigación. Editorial Jurídica de Chile.

Huaylla Marín, J. A. (2015). Intervenciones corporales sin el consentimiento del Imputado en el código procesal penal de 2004. [Tesis de maestría, Universidad Privada Antenor Orrego]. Repositorio Nacional UPAO. http://repositorio.upao.edu.pe/handle/upaorep/2258.

Valdez Caldas, J. M. (2018). Informe policial y su influencia en la formalización de la investigación preparatoria en el marco del modelo procesal acusatorio garantista en el distrito judicial de Huaura, periodo 2016-2017. [Tesis de doctorado, Universidad Nacional José Faustino Sánchez Carrión]. Repositorio Institucional UNJFSC. http://www.repositorio.unjfsc.edu.pe

Huertas-Martín, M. I. (1999) El sujeto pasivo del procedimiento penal como objeto de la prueba. Editorial Bosch.

Instrucción No.7 de 1999 de la Fiscalía General de la República.

Landaverde, M. (2017). Intervenciones corporales. Revista Enfoque Jurídico. https://enfoquejuridico.org/category/realidades-judiciales/

Levenne, R. (1993). Manual de derecho procesal penal. Tomo I. (2. ${ }^{\text {a }}$ ed.). Editorial Depalma.

Ley de Enjuiciamiento Criminal Española. Tomada de: https://confilegal.com/20171101-ley-enjuiciamiento-criminal-actualizada/

Ley de Procedimiento Penal Cubana (Actualizada) Ley No. 5 de 13 de agosto de 1977. G.O. Ordinaria No.37 de fecha 26 de agosto de 1977. Actualizada en Gaceta Oficial. Febrero 2020. 
Ley No. 41 de Salud Pública de 1983.Gaceta Oficial. Asamblea Nacional del Poder Popular en Sesión Ordinaria, celebrada el 13 de julio de 1983, correspondiente al Cuarto Periodo Ordinario de Sesiones de la Segunda Legislatura.

López Camacho, A. M. (2015). La importancia de la inspección del lugar de los hechos en la cadena de custodia de la prueba. https://www. monografias.com/trabajos105/.

Lucena Toro, O. A. (2010). Intervenciones corporales y derechos fundamentales: límites. Revista Criterio jurídico garantista. 2(3). https//: www.fuac.edu.co

Medina Batista, D. (2015). El imputado en el proceso penal: una visión desde los derechos y garantías fundamentales. Revista Pensamiento Penal. https//:www.pensamientopenal.com.ar.

Morales Aguilera, M. (2015). Diligencias de investigación fiscal. Editorial Civitas, Aranzadi. Morales Aguilera, M. (2015). Diligencias de Investigación fiscal. Editorial Aranzadi. https://www.researchgate.net/publication/328654749.

Moras Mom, J. R. (2004). Manual de derecho procesal penal. Editorial Lexis Nexis Abeledo-Perrot.

Pedraz Penalva, E. (2002). Introducción al derecho procesal penal. (2. a edición). Editorial Hispamer.

Real Academia Española. (2007). Diccionario de la lengua española. (22. ${ }^{\text {a }}$ ed.).
Resolución 100 de 2008 del Ministerio de Salud Pública. Tomada de https://salud.msp. gob.cu.

Resolución 458 de 2019 del Ministerio de Salud Pública. Tomada de https://salud.msp. gob.cu.

Rivero García, D. (2014). Estudios sobre el proceso penal. Ediciones ONBC.

Roxin, C. (2000). Derecho procesal penal. Editores del Puerto S.R.L.

Rubio Sánchez, A. (2016). El uso del Test P300 en el Proceso Penal Español: Algunos aspectos controvertidos. Revista Electrónica de Ciencia Penal y Criminología. http://criminet. ugr.es/recpc/18/recpc18-04.pdf

Sánchez Carmona, P. P. (1997). Actos de investigación que requieren la autorización previa del juez de control. Universidad Nacional Autónoma de México.

Sentencia del Tribunal Constitucional Español 207/1996. (BOE núm. 19, de 22 de enero de 1997). ECLI:ES:TC: 1996:207. La Sala Primera del Tribunal Constitucional. https:// hj.tribunalconstitucional.es

Vázquez Ganoza, C. Z. (2005). Aplicación coactiva de las medidas limitativas de derechos en el Código Procesal penal de 2004. Actualidad Procesal Penal, Gaceta jurídica, tomo 190. Vázquez Rossi, J. E. (1997). Derecho procesal penal. Tomo II. El proceso penal. Editorial Rubinzal-Culzoni. 